\section{Our Tax Dollars at Work}

April, in the Northern Hemisphere, means spring! Spring weather, spring flowers, spring holidays, and, jarring as it is against this enlivening background, the income tax filing deadline in the United States and many other countries. Since we all pay taxes, and we all have an interest in the success of the materials enterprise, it behooves us to understand the connection between the two, and how the Materials Research Society is increasingly involved in efforts to encourage the government to direct resources and attention toward materials-oriented research that benefits society as a whole.

Most obviously, many of us perform research financed wholly or in part with government funds. The largest granting agencies and national laboratories are run with money appropriated from tax receipts. In addition, there are governmentsponsored programs available to support "high-risk" projects within private companies, such as the Small Business Innovation Research and Small Business Technology Transfer programs, and the National Institute of Standards and Technology Advanced Technology Program in the United States. Less prominent are research incentives based on the opportunity for businesses to decrease their tax payments in return for investing in research. For example, the United Kingdom offers a generous tax credit for research by smalland medium-sized companies. The U.S. government and those of many states include tax deductions for engaging in technological development that has some degree of uncertainty, and of anticipated economic development, associated with it.

One difficulty with the federal research tax credit is that it rewards large increments in research investment, but not continuing research investment, even when such sustained programs are at high levels, as is the case with large, R\&Dcentric companies. The fact that the tax credit provisions are not permanent also works against participation by major companies. Yet another drawback is that

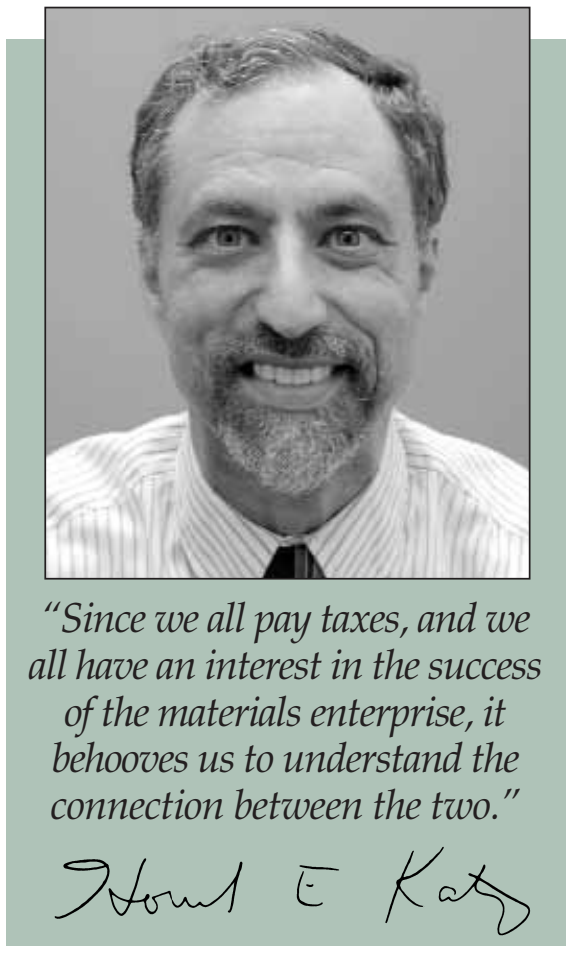

much collaborative industrial research involving universities is excluded. New approaches are needed not only to advocate directly for the expansion of these tax incentives, but to point out how much economic growth is traceable to the research done by institutions of all types and sizes. The purchases made and salaries paid in the course of doing the research itself represent significant economic activity, and the students thereby trained are the source of future innovation and entrepreneurship.

MRS is already involved in congressional activities aimed at support for the large funding agencies, including the National Science Foundation (NSF), the Department of Energy (DOE), and the Department of Defense (DoD). These efforts range from one-on-one meetings with congressional staff to participation in large, multisociety

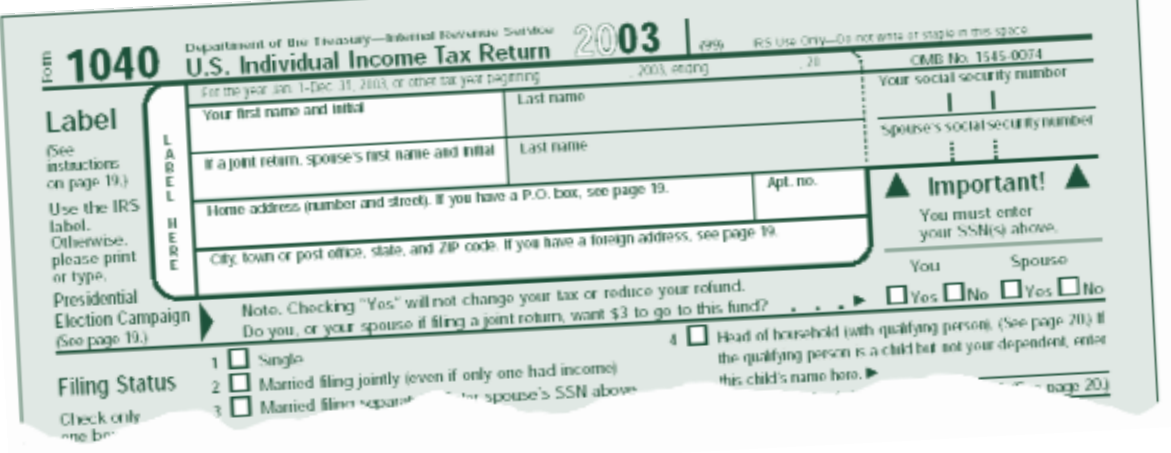

organizations like the Alliance for Science \& Technology Research in America (ASTRA), which was created to amplify the pro-physical science message of each of its constituent groups. We maintain a professional representative in Washington, and also support Congressional Fellows in legislative offices who help educate our senators and representatives about the value of materials research. Authorization bills that endorse increased funding for NSF in particular were passed partly in response to such efforts. However, as evidenced by the minimal physical science outlays in the budget proposal currently under discussion in Washington, the hard work of translating the authorizations into actual appropriations (dollars!) remains, especially regarding the funding of independent investigators in materials science, physics, and chemistry.

Government funding seminars at our major meetings allow for interaction of many MRS members with potential research sponsors. NSF, DOE, DoD, and the new Homeland Security Department have been frequent participants. Our forums on intercontinental research programs help promote and develop funding opportunities for international collaboration. We participate in associated events at meetings of non-U.S. materials research societies and summit meetings as well. All of this is led by one of our major volunteer groups, the Public Affairs Committee.

We are also in the process of beginning some new outreach initiatives. In January, a meeting of MRS leadership with directors at the National Institutes of Health resulted in plans for an increased NIH presence at our meetings and an increased awareness at NIH of the important role that the materials community can play in shaping future medical platforms. We also anticipate an expansion of visiting scientist programs for materials researchers to become more familiar with life science research. Additional coverage of our NIH outreach activity appears elsewhere in this issue of MRS Bulletin, in the PUBLIC AFFAIRS FORUM.

We all know that the political landscape is constantly shifting. We welcome any insight that members may bring, both proactively and in response to solicitations, concerning government support for their activities, including the government's role in enabling research both inside and outside the United States. We also invite any interested members to become involved personally in our ongoing public affairs activities. 2004 MRS President 